\title{
An improved technique for identification of mathematical model parameters of thermal power equipment and assessment of its performance
}

\author{
Aleksandr Kler ${ }^{1}$, Vitalii Alekseiuk ${ }^{1 *}$, and Aleksei Maksimov ${ }^{1}$ \\ ${ }^{1}$ Melentiev Energy Systems Institute of Siberian Branch of the Russian Academy of Sciences, Irkutsk, Russia
}

\begin{abstract}
The problems of state estimation of thermal power system operation and identification of mathematical model parameters have not been acceptably solved due to the complexity of studied objects and their mathematical models, and the lack of effective methods, algorithms and computer programs to solve the required mathematical problems. The results of solving the indicated problems are of importance as such, and play a great part in the qualitative solution to the problems of thermal power equipment control, e.g., the problems of optimal load dispatch among thermal power plant units and optimal control of thermal power equipment operation conditions. The paper describes a technique improved by the author for identification (adjustment, verification) of mathematical model parameters for complex thermal power equipment. The technique allows us to more effectively detect gross errors in measurements of control parameters used for identification of the mathematical model of the studied equipment, to evaluate correctness and rectify errors in the mathematical model construction, and to improve identification accuracy. An improved technique for identification of mathematical model parameters was tested on a detailed mathematical model of the present-day $225 \mathrm{MW}$ generating unit that was constructed by the author. The paper presents results of solving the identification problem of mathematical model parameters of a generating unit and an example of the optimization calculation of the real operation condition in order to reduce specific fuel consumption for electricity generation. In addition, the paper discusses an issue of assessing the identification accuracy of mathematical model parameters of thermal power equipment that depends on the accuracy of measurements of control parameters used to adjust the model, as well as on the correctness of the mathematical model construction and the calculation technique applied.

Keywords: identification of parameters, mathematical modeling, accuracy criterion, measured control parameters, model adjustment, real-time control, relative discrepancies, operation conditions, state estimation, coal-fired generating unit.
\end{abstract}

Financing: The research was carried out under State Assignment, Project 17.1.4 (reg. no. AAAA-A17117030310449-7) of the Fundamental Research of Siberian Branch of the Russian Academy of Sciences.

\section{Introduction}

Thermal power plants (TPPs) on fossil fuel continue to form the basis of electric power industry in the Russian Federation, especially in the regions of Siberia and the Far East. The thermal power units consume an essential portion of produced fossil fuel and other resources. Hence, the problems of improving the energy and economic operation effectiveness for such units are most topical and noteworthy.

Note that the operation effectiveness of thermal power units (TPUs) directly depends on operating conditions and real-time control of equipment. To improve the control efficiency of power plant equipment, in turn, the operation personnel should have a "feedback", in other words, monitor changes in equipment parameters and its characteristics difficult or impossible to meter (burnt fuel consumption, generating unit efficiency, specific fuel consumption, etc.) with change in the control actions.

Besides, the real state of thermal power equipment changes during operation, for example, due to deposition of salts in the turbine flow part, pollution of the heat exchange surfaces of boilers, regenerative heaters and others, which influence operation conditions of equipment and its efficiency. Thus, the problem of assessing the state of main thermal power equipment at thermal power plants (TPPs) is critical for real-time control of operation conditions of TPUs.

The present-day thermal power units such as coalfired generating units and their boiler units, steam turbines and other auxiliary equipment are technical systems with highly complicated flow diagrams, diverse elementary composition and operation conditions. 
Therefore, the methods of mathematical modeling and optimization of schemes and parameters are the main tools to study thermal power equipment at TPPs.

The keystone for application of the methods of mathematical modeling and optimization of thermal power equipment and thermal power plants was laid in the early works by the scientists at Melentiev Energy Systems Institute. The works by G.B. Levental and L.S. Popyrin focus on optimization of continuous and discrete parameters of TPUs of different types and flow diagrams, present principles of mathematical modeling automation of TPUs and describe approaches to optimization of such equipment under uncertainty of initial information $[1,2]$. The methods of mathematical modeling of thermal power units were evolved by the Russian scientists: F.A. Vulman [3], A.A. Palagin [4], V.M. Borovikov [5].

The problems of state estimation and identification of mathematical model parameters for calculation of operation conditions of power systems considering errors in measurements were studied by A.Z. Gamm and his colleagues. Their work [6] describes approaches to detection of gross errors in measurements called "bad" data that are based on the method of test equations.

The problems of state estimation and identification of mathematical model parameters were also treated in the studies of pipeline systems. The work by N.N. Novitsky, which presents a comprehensive analysis of some problems and methods for state estimation that were devised considering specific features of hydraulic circuits, is among such studies [7].

The works by G.V. Nosdrenko, Yu.V. Ovchinnikov [8] and G.D. Krokhin, M.Ya. Suprunenko [9] were among the first on this topic as applied to the thermal power industry. They present a technique for coordination of the heat and energy balance equations to solve the state estimation problem. However, the indicated works neither present the statement and solution of the identification problem of control parameters that cannot be metered directly, nor study the relationship between optimal solutions and errors in measurements.

The Department of Thermal Power Systems at Melentiev Energy Systems Institute has gained rich experience in the study of complex thermal power units and thermal power plants. The works by A.M. Kler and N.P. Dekanova are among the early works that focus on approaches to optimization of mathematical models of thermal power units at real-time control of operation conditions of CHPPs $[10,11]$. A coordinated technique for the studied equipment diagnostics that is based on the joint solution of extremum optimization problems of state estimation and identification of characteristics of TPUs was proposed by A.V. Mikheev [12]. Moreover, an approach to the improvement of initial information quality by elimination of errors in the bad metered parameters is suggested in the work [13]. The studies by A.M. Kler, A.S. Maximov and E.L. Stepanova $[14,15]$ are among the latest works devoted to this topic. They focus on development of "high-speed" mathematical models of main equipment at TPPs to perform complex optimization calculations of operation conditions of
CHPPs, and also describe a technique for adjustment of mathematical models to a real state of the studied equipment. The technique allows the adjustment of mathematical model coefficients so that the obtained results correspond most accurately to the real equipment state, which validates optimization solutions.

The insufficiently extensive application of the effective methods of mathematical modeling, in general and their use to control operation conditions of TPPs, in particular are explained by some difficulties, such as significant complexity of mathematical models of current TPUs and need to adjust these models to the real equipment state changing in the course of time.

Thus, in practice the problems of thermal power system state estimation and identification of mathematical model parameters have no feasible solution due to the complexity of the studied objects and their mathematical models, and the lack of effective methods, algorithms and computer programs to solve the required mathematical problems. The results of solving the indicated problems are important as such and play an essential role for the qualitative solution of TPU control problems, e.g., for the optimal load dispatch among TPP units and the optimal control of operation conditions of TPUs and TPPs.

\section{Description of the improved technique for identification of mathematical model parameters of thermal power equipment}

As was noted above, the works [14, 15] present techniques for adjustment (identification) of the mathematical model parameters of the studied thermal power equipment based on the measurements of control parameters that were taken during the tests on real equipment. These techniques, however, have two shortcomings, which, in specific situations, can prevent from successful solution of the stated problem.

First, the problem is solved successfully in case of lack of gross errors in the measurements among the metered parameters. However, in case of "bad" measurements with gross errors in any considered operation condition, the errors are redistributed among different metered parameters in one operation condition and, which is more important, among different conditions. Such redistribution prevents from the unique determination of an erroneous measurement and leads to incorrect solutions. The numerous calculations using several mathematical models have showed that practically there are always one or several "bad" measurements of control parameters in different operation conditions that cause a raw error in the final identification accuracy. This note is particularly true to old equipment with low accuracy sensors.

Second, the indicated techniques do not take into consideration the mathematical model errors of the studied equipment. The models of the main thermal power equipment at TPPs are based on the standard calculation methods and do not always describe real processes accurately enough. Moreover, at the stage of modeling the author often applies some simplifications, 
e.g., neglect of a minor heat carrier flow in the flow diagram of TPU. This fact causes additional errors which should be taken into consideration in identification of the mathematical model parameters.

This paper presents a new improved identification technique. The backbone of the idea is to develop a new comprehensive technique consisting of three stages to solve the above problems and to improve the accuracy of mathematical model identification.

At the first stage of the identification problem solution the incorrect measurements of control parameters are revealed and eliminated from further calculations. The incorrect measurements are the values of the metered parameters that exceed the declared accuracy of sensors used in the tests. Such measurements can be detected by solving the minimization problem of the auxiliary coefficient $\psi$ for each individual operation condition of equipment. The coefficient $\psi$ corresponds to the value of the maximum relative deviation among all the metered parameters. The mathematical statement of the first identification stage is the following:

$$
\min _{X_{m}, X_{\text {um }}, \theta, \psi} \psi
$$

subject to:

$$
\begin{gathered}
H\left(y_{m}, x_{m}, x_{u m}, \theta\right)=0 \\
G\left(y_{m}, x_{m}, x_{u m}, \theta\right) \geq 0 \\
x_{m j}-\psi \cdot \sigma_{x j} \leq \overline{x_{m j}} \leq x_{m j}+\psi \cdot \sigma_{x j} \\
y_{m k}-\psi \cdot \sigma_{y k} \leq \overline{y_{m k}} \leq y_{m k}+\psi \cdot \sigma_{y k} \\
\sigma=\frac{X B \cdot \alpha}{3 \cdot 100}
\end{gathered}
$$

where $H$ is the function of equality constraints that includes all equations of the mathematical model and its elements (equations of heat transfer, heat balance and others); $G$ is the function of inequality constraints that includes physical and operating constraints on real equipment operation; $\psi$ is the coefficient equal to the absolute maximum relative deviation of parameters (the parameters calculated by the mathematical model are with the upper bar, the parameters obtained by measurements on the real equipment - without the bar); $\sigma_{x}^{2}, \sigma_{y}^{2}$ are the measurement error variances of the vectors $x_{m}$ and $y_{m}$, respectively, $X B$ is the upper limit of the sensor measurement; $\alpha$ is the class of sensor precision (in \%).

The mathematical model parameters of the identification problem can be divided conventionally as follows: the parameters of $x_{m}$ that are metered on the studied unit and are the input information for the mathematical model; the metered parameters of $y_{m}$ that are the output information for the mathematical and the parameters of $x_{u m}$ that are not metered on the real unit and are the input information for the model. The array of the adjustable coefficients $\theta$ of the mathematical model is selected for each model individually. They are intended to influence physical processes occurring in the mathematical model elements. Usually such parameters comprise coefficients of thermal efficiency of boiler heat transfer surfaces, hydraulic resistances of heat exchangers, internal relative coefficients of turbine compartments and others.

The use of the so called "three-sigma" rule in this study is explained by the fact that the probability belief in this case equals 0.997 . Therefore, it is possible to reasonably argue that all possible random errors in measurements with the normal distribution do not practically exceed 3 sigma in the absolute value. In equations $(4,5,10,11)$ the minimized auxiliary coefficient $\psi$ specified initially by the large numbers 60 100 is used instead of the multiplier equal to 3 . This substitution is necessary for considering the errors of the applied sensors and the imperfection of the calculation technique, as well as the errors in mathematical models. In the process of the optimization calculation $(1,7)$ this coefficient tends toward the value 3 , but in practice it often takes somewhat lower value. Thus, the suggested technique makes it possible to evaluate an additional error caused by the imperfection of the standard calculation methods and simplifications included in the mathematical model of the studied TPU.

To determine erroneous measurements, it is needed to reveal active constraints on the deviation of the parameter metered on the unit from the parameter calculated on the mathematical model. The measurement value in this constraint can be treated as erroneous and excluded from further consideration. The calculations have showed that such an approach makes it possible to more effectively detect measurement errors and minimizes redistribution of erroneous measurements among the parameters in different operation conditions.

It is noteworthy that the calculations at this stage are not always possible. This concerns thermal power units with an insufficient number of sensors and hence, insufficient amount of initial information for identification for an individual condition. If the number of measurements is approximately the same or exceeds the number of adjustable coefficients, the calculations at this identification stage are possible. Otherwise, the second identification stage that is performed for several conditions concurrently is necessary. In such a case the number of control parameter measurements will be satisfactory to successfully solve the stated problem.

At the second stage of the identification problem solution the mathematical model of the studied equipment is tested for availability of modeling errors and elimination of remaining gross errors in measurements.

The statement of the optimization problem is similar to the problem solved at the first stage, except that it is solved for all considered conditions concurrently (as evidenced by the index $i$ indicating the sequence number of equipment operation condition).

The problem is formulated as follows:

$$
\min _{X_{m}^{i}, X_{u m}^{\prime}, \theta, \psi} \psi \text {, }
$$

subject to

$$
H\left(y_{m}^{i}, x_{m}^{i}, x_{u m}^{i}, \theta\right)=0
$$




$$
\begin{gathered}
G\left(y_{m}^{i}, x_{m}^{i}, x_{u m}^{i}, \theta\right) \geq 0 ; \\
x_{m j}^{i}-\psi \cdot \sigma_{x j} \leq \overline{x_{m j}^{i}} \leq x_{m j}^{i}+\psi \cdot \sigma_{x j} ; \\
y_{m k}^{i}-\psi \cdot \sigma_{y k} \leq \overline{y_{m k}^{i}} \leq y_{m k}^{i}+\psi \cdot \sigma_{y k}
\end{gathered}
$$

The calculations have showed that the solution to this problem allows the incorrect description of processes occurring in TPUs by the mathematical model to be detected. If the solution yields the parameters with a significant deviation of measurements in different equipment operation conditions, then it points to the lack of the required coefficient in the list of adjustable ones or the inaccurate construction of the mathematical model. Besides, the minor heat carrier flows that are neglected in the mathematical model construction for the studied equipment can cause an additional error in identification. Therefore, at this stage of calculations it is possible to make required changes in the model structure describing specific features of the studied thermal power equipment.

At the third stage of the identification problem solution the following optimization problem is solved.

$$
\min _{\substack{x_{m}^{i}, x_{u m}^{i}, \theta \\ x_{u m}}} f\left(y^{i}, x_{m}^{i}, x_{u m}^{i}, \theta\right)
$$

subject to:

$$
\begin{gathered}
H\left(y_{m}^{i}, x_{m}^{i}, x_{u m}^{i}, \theta\right)=0 \\
G\left(y_{m}^{i}, x_{m}^{i}, x_{u m}^{i}, \theta\right) \geq 0 \\
x_{m j}^{i}-\psi \cdot \sigma \sigma_{x j} \leq \overline{x_{m j}^{i}} \leq x_{m j}^{i}+\psi \cdot \sigma_{x j} \\
y_{m k}^{i}-\psi \cdot \sigma_{y k} \leq \overline{y_{m k}^{i}} \leq y_{m k}^{i}+\psi \cdot \sigma_{y k} \\
f=\sum_{i=1}^{R}\left[\sum_{j=1}^{N} \frac{\left(x_{m j}^{i}-\overline{x_{m j}^{i}}\right)^{2}}{\sigma_{x j}^{2}}+\sum_{k=1}^{M} \frac{\left(y_{m k}^{i}-\overline{y_{m k}^{i}}\right)^{2}}{\sigma_{y k}^{2}}\right]
\end{gathered}
$$

where $f$ is the objective function in equation 17 (the parameters calculated on the mathematical model are indicated by the upper bar, the parameters metered on the real equipment are given without the bar); $R$ is the number of calculated conditions; $N$ is the dimension of the vectors $x_{m} ; M$ is the dimension of the vectors $y_{m}$.

The third identification stage aims to achieve the maximum possible closeness between the real equipment operation and the calculations on the mathematical model. The objective function $f$ (17) contrary to the auxiliary coefficient $\psi(1,7)$ is the sum of squares of all relative discrepancies of control parameters in all equipment operation conditions. Hence, at the third stage it is possible to reduce both all relative discrepancies of the metered parameters and the maximum discrepancy at the second stage. After identification termination, the values of the adjustable coefficients $\theta$ of the mathematical model are fixed and not subject to further changes, and the mathematical model is considered adjusted to the real equipment state.

Note that all identification stages are solved strictly in sequence and take into account changes in the mathematical model that are made at the previous stages.

\section{Results of identification of mathematical model parameters for the studied generating unit}

In this study the present-day generating unit installed at the Kharanor condensing power plant (Yasnogorsk settlement, Trans-Baikal Territory) was taken as a prototype for the mathematical model. It consisted of a $225 \mathrm{MW}$ steam turbine unit K-225-12,8-3P and a high pressure reheat boiler unit ЕП-630-13,8-565 БТ with a rating of $630 \mathrm{t} / \mathrm{h}$. The flow diagrams and the mathematical models of the turbine and boiler units are described in greater detail in the papers $[17,18]$.

The mathematical model of a generating unit was constructed by the author using the software "System of computer-based construction of programs" developed at Melentiev Energy Systems Institute of SB RAS [19]. The calculation scheme of the generating unit comprises 100 elements and 169 ties between them. The obtained mathematical model contains 1153 input parameters, 1388 output parameters, 56 parameters of which are calculated iteratively and should be set with an initial approximation.

The calculation results obtained with the help of the improved technique developed by the author for identification of mathematical model parameters of thermal power equipment are given with respect to the described generating unit.

The values of the metered parameters at the scheme control points that are necessary for identification of mathematical model parameters were taken from the sensor readings given by the engineering personnel of the power plant. The accuracy class of the applied sensors are: for the sensors metering electric load - $1 \%$, pressure $-1.5 \%$, water and steam temperature $-2 \%$, flow rate $-3 \%$, gas temperature $-5 \%$. The calculations were made for three selected operation conditions of the generating unit (the minimum load $125 \mathrm{MW}$, the load $227 \mathrm{MW}$ and the maximum load $235 \mathrm{MW}$ ), each containing 60 metered parameter values at different flow diagram points, of which 5 metered parameters are the input (preset) information for the mathematical model and 55 parameters are the output (calculated) information for the mathematical model.

At the first identification stage the formed optimization problem (equations 1-6) comprised 76 optimized parameters and 313 inequality constraints for each considered operation condition. The array of the optimized parameters consisted of 59 adjustable model coefficients $(\theta) ; 11$ parameters unmetered at the generating unit, such as fuel amount burnt in the boiler, excess air coefficient in the furnace, injections into 4 stages of steam coolers, heads of the main pumps of the main condenser duct, controllers of the superheated steam and minimized auxiliary coefficient $(\psi) ; 5$ measurements that are the input information for the mathematical model.

The array of the inequality constraints consisted of 120 constraints on the minimum and maximum values of 
the calculated control parameter values subject to sensor accuracy $(10,11) ; 192$ physical constraints on the nonnegativity of heat carrier flow rate in all model elements, the temperature head, the temperature and mechanical strength of boiler unit elements and some others; 4 operating constraints on the primary and secondary steam temperature, the turbine unit capacity and the flue gas temperature.

The calculations for each operation condition revealed some ambiguous measurements, namely pressure values at the inlet into some turbine compartments and steam flow rate 3 at the condenser inlet. The measurement values presented by the power plant personnel were objectively tested by the steam expansion diagram constructed in the $h, s$-diagram in Fig. 1.

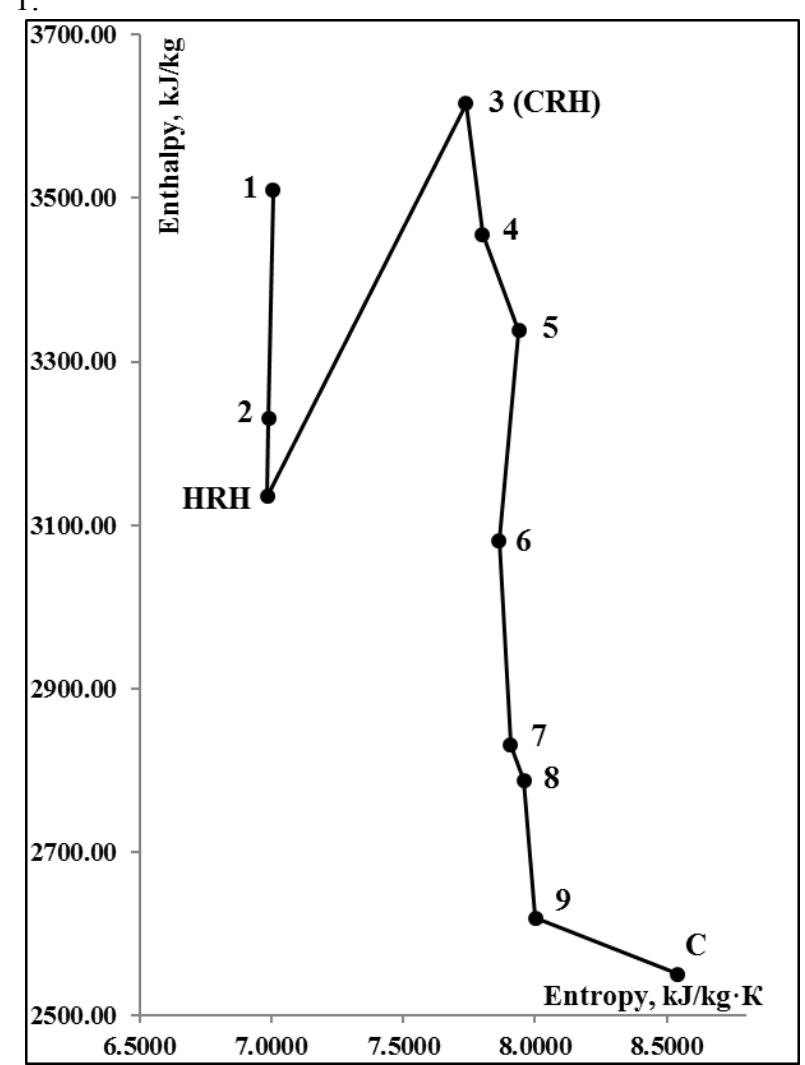

Fig. 1. Steam expansion process in the turbine unit for one operation condition in the $h, s$-diagram

The diagram figures indicate the number of turbine compartment with the steam pressure metered at its inlet (CRH - the steam coming to the cold pipeline of the steam reheat after expansion in the high pressure cylinder, HRH - the steam coming to the intermediate pressure cylinder from the hot pipeline of the steam reheat, $\mathrm{C}$ - turbine unit condenser).

There were no pressure measurements of the steam coming to the turbine compartments 7 and 9 , as well as temperature measurement at the outlet from compartment 8 , because the pressure and temperature sensors were not installed at these points, and therefore their values were set approximately. Besides, the pressure measurements at the inlet to compartments 2 and 5 caused doubt, as far as the internal relative efficiency of the turbine compartment cannot exceed thermodynamically $100 \%$ (slope of the steam expansion diagram toward entropy decrease). Hence, these measurements are inaccurate and should be excluded from further calculations. In addition, it was decided to exclude the water flow rate at the condenser outlet from the metered parameters due to the gross discrepancy of the values of this parameter in two operation conditions.

The similar calculations of two remaining conditions on the mathematical model of the generating unit led to the same results. Thus, at the first identification stage 6 measurements were excluded in each considered operation conditions because of data lack or gross errors in measurements.

At the second identification stage the formed optimization problem (equations 7-11) comprised 109 optimized parameters and 909 inequality constraints. At this stage, contrary to the first, the problem was formed for three considered conditions jointly, which made it possible to refine the values of the array of adjustable coefficients subject to the effect of operation condition change on the thermal and energy efficiency of the generating unit elements.

In the previous work [20] the author suggested that the mathematical model elements be tested for modeling correctness and the corresponding changes be made at this identification stage. For example, the active constraint on the pressure measurement in the deaerator can indicate that this parameter changes nonlinearly with transition to the other condition, which should be taken into consideration in the mathematical model for the generating unit element replacing the adjustable coefficient (the throttling coefficient of steam that is delivered to the deaerator) with the quadratic dependence of type $k_{d}=A \cdot x^{2}+B \cdot x+C$, where $k_{d}$ is the throttling coefficient, $x$ is the deaerator feed water flow rate that characterizes the turbine operation condition; $A, B, C$ are the new optimized coefficients of the identification problem. Similar refinements of the mathematical models can be necessary in case of a sensible change in the internal relative coefficients of the turbine compartments from one condition to the next.

It is noteworthy that at the second identification stage the minimized objective function is the auxiliary coefficient being the maximum relative discrepancy (divergence between the measurement and the calculation of the control parameter subject to the corresponding sensor accuracy) or the relative discrepancies, if they are several. The calculations have showed that the considered minimax criterion vividly indicates the mathematical model "bottlenecks" for the studied TPU and assists in detection of gross errors in the control parameter measurements simply enough.

As applied to the studied generating unit the changes made at the second identification stage allowed the objective function to be minimized to the value 3.83 . As was said above, the method is based on the three sigma rule, which means that the error equal to 3.0 or lower is perfectly explained by the declared sensor accuracy. The additional error equal in this case to 0.83 can be explained by the imperfection of the standard methods for calculation of boiler and turbine units, as well as the 
required assumptions in the mathematical model of the generating unit.

At the third identification stage the formed optimization problem (equations 12-17) included 108 optimized parameters and 909 inequality constraints. The auxiliary coefficient $\psi$ minimized at the second identification stage was excluded from the list of optimized parameters and fixed at the value 3.9. The maximum discrepancy as at the second stage and all discrepancies in all operation conditions were optimized at this stage. Thus, optimization of the objective function (17) can lead to the maximum agreement between the calculations on the mathematical model and the measurements on the real equipment without increasing the maximum discrepancy value. Minimization of the objective function (17) with reference to the considered generating unit model (17) produced a meaningful result. The function value reduced from 6940 (the second identification stage) to 1573 (after termination of the third stage).

After termination of the third identification stage, the values of the adjustable coefficients $\theta$ of the mathematical model were fixed and the mathematical model was considered as adjusted to the real equipment state.

The described technique allows assessing the identification of mathematical model parameters of the studied thermal power equipment. The absolute relative discrepancies of control parameters ( $x$ is the input information for the model, $y$ is the output information) are taken as the criterion. The discrepancies are calculated by the formulas:

$$
k_{x}=\frac{\left|x_{m}-\overline{x_{m}}\right|}{\sigma_{x}} ; \quad k_{y}=\frac{\left|y_{m}-\overline{y_{m}}\right|}{\sigma_{y}}
$$

The overall accuracy of the identification problem solution can be obtained by calculation of the sum of the absolute relative discrepancies in control parameters in all considered operation conditions by the formula:

$$
k=\sum_{i=1}^{R}\left[\sum_{j=1}^{N} \frac{\left|x_{m j}^{i}-\overline{x_{m j}^{i}}\right|}{\sigma_{x j}}+\sum_{k=1}^{M} \frac{\left|y_{m k}^{i}-\overline{y_{m k}^{i}}\right|}{\sigma_{y k}}\right]
$$

where $R$ is the number of calculated operation conditions; $N$ is the dimension of the vectors $x_{m} ; M$ is the dimension of the vectors $y_{m}$.

In the considered generating unit model the value of the criterion $k$ after the second identification stage was equal to 511. After minimization of the sum of squares of relative discrepancies at the third stage, the value of criterion (19) considerably decreased and became equal to 332 . Thus, the total relative discrepancy of control parameters decreased by $35 \%$, which made it possible to adjust the mathematical model subject to the real generating unit state even more accurately.
Table 1 presents the values of all control parameters (the value calculated on the mathematical model is given above, the value measured on the generating unit is given below). The value of criterion (18) that characterizes the closeness between the calculated and measured values is given to the right of the parameter values. The closer is this value to zero, the lower is the relative discrepancy of the corresponding measurement. The parameters, whose measurements are absent (or were given approximately) or were excluded at one of the identification stages of the generating unit model are showed in the Table by filling. These measurements were excluded from further calculations.

\section{Example of the optimization calculation on the adjusted generating unit model}

Identification of mathematical model parameters of the studied equipment, inter alia, allows the solution of some critical operational problems, for example, the state estimation of thermal power equipment or optimization of schemes and parameter of the studied equipment at TPP in order to improve efficiency of its operation. The single calculation of operation condition on the adjusted generating unit model takes only several seconds (3-5 seconds), which makes possible its application to realtime control of the generating unit.

The calculation on the generating unit model adjusted to the real equipment state is taken as an example of the optimization calculation. The objective function is the specific consumption of coal equivalent burnt in the boiler unit. The array of inequality-constraints included both physical constraints (on the temperature of pipe metal, mechanical metal stress, non-negativity of steam flow rates and others), and operating constraints (the temperature of primary and secondary steam, pressure in the condenser, turbine capacity). Table 1 presents a composition and values of the optimized parameters (lines 1-9), controlled operating parameters (lines 1014), and values of the efficiency indicators of generating unit operation (lines 15,16) in one of the considered conditions and in the optimal condition obtained as a result of optimization calculation. The optimization calculation on the generating unit model takes several tens of minutes (30-60 minutes depending on the number of optimized parameters and inequality-constraints).

As is seen from the Table, the volume of fuel burnt in the boiler unit can considerably be decreased at the same electricity generation influencing the operating parameters of the generating unit, which somewhat increases its operation efficiency. In the above example, the specific consumption of coal equivalent for net electricity generation (227 MW of power) decreased by $3.2 \%$, and the net efficiency of the generating unit increased approximately by the same value. 
Table 1.Calculation results, measurements of control parameters and values of criterion accuracy for three operation conditions of the studied generating unit model

\begin{tabular}{|c|c|c|c|c|c|c|c|}
\hline No & Parameter, measurement unit & 1 cond. & $k_{i}$ & 2 cond. & $k_{i}$ & 3 cond. & $k_{i}$ \\
\hline 1 & 2 & 3 & 4 & 5 & 6 & 5 & 6 \\
\hline 1 & Circulating water temperature before condenser & $\begin{array}{l}22.23 \\
22.05\end{array}$ & 0.536 & $\begin{array}{l}22.34 \\
21.65\end{array}$ & 2.063 & $\begin{array}{l}21.07 \\
21.25\end{array}$ & 0.526 \\
\hline 2 & Circulating water flow rate before condenser & $\begin{array}{l}10253 \\
10211\end{array}$ & 0.278 & $\begin{array}{l}10872 \\
10979\end{array}$ & 0.712 & $\begin{array}{l}10211 \\
10143\end{array}$ & 0.451 \\
\hline 3 & Feed water temperature before condenser & $\begin{array}{l}32.2 \\
32.0\end{array}$ & 0.602 & $\begin{array}{l}31.0 \\
30.9\end{array}$ & 0.159 & $\begin{array}{l}32.3 \\
32.2\end{array}$ & 0.159 \\
\hline 4 & Air temperature before primary tubular air heater & $\begin{array}{l}48.5 \\
46.1\end{array}$ & 0.747 & $\begin{array}{l}47.0 \\
48.7\end{array}$ & 0.493 & $\begin{array}{l}46.0 \\
49.5\end{array}$ & 1.026 \\
\hline 5 & Steam pressure after second turbine compartment & $\begin{array}{l}32.75 \\
32.91 \\
\end{array}$ & 0.794 & $\begin{array}{l}19.38 \\
19.32 \\
\end{array}$ & 0.293 & $\begin{array}{l}34.12 \\
34.07 \\
\end{array}$ & 0.292 \\
\hline 6 & Steam pressure before first turbine compartment & $\begin{array}{l}127.26 \\
128.16 \\
\end{array}$ & 0.723 & $\begin{array}{l}74.52 \\
70.44\end{array}$ & 3.262 & $\begin{array}{l}133.56 \\
132.75\end{array}$ & 0.700 \\
\hline 7 & $\begin{array}{l}\text { Steam pressure before second turbine } \\
\text { compartment }\end{array}$ & $\begin{array}{l}47.48 \\
46.39 \\
\end{array}$ & 3.360 & $\begin{array}{l}27.73 \\
26.99\end{array}$ & 2.276 & $\begin{array}{l}49.45 \\
49.50\end{array}$ & 0.151 \\
\hline 8 & Steam pressure before third turbine compartment & $\begin{array}{l}27.896 \\
28.590\end{array}$ & 3.469 & $\begin{array}{l}16.12 \\
16.00\end{array}$ & 0.596 & $\begin{array}{l}28.98 \\
29.69\end{array}$ & 3.787 \\
\hline 9 & Steam pressure before fourth turbine compartment & $\begin{array}{l}15.81 \\
15.82\end{array}$ & 0.119 & $\begin{array}{l}9.09 \\
9.17\end{array}$ & 0.623 & $\begin{array}{l}16.42 \\
16.41\end{array}$ & 0.110 \\
\hline 10 & Steam pressure before fifth turbine compartment & $\begin{array}{l}9.46 \\
9.25 \\
\end{array}$ & 4.118 & $\begin{array}{l}5.46 \\
4.64 \\
\end{array}$ & 16.42 & $\begin{array}{l}9.83 \\
9.60 \\
\end{array}$ & 4.856 \\
\hline 11 & Steam pressure before sixth turbine compartment & $\begin{array}{l}3.85 \\
3.89\end{array}$ & 2.018 & $\begin{array}{l}2.26 \\
2.30\end{array}$ & 2.154 & $\begin{array}{l}4.01 \\
4.01\end{array}$ & 0.139 \\
\hline 12 & $\begin{array}{l}\text { Steam pressure before seventh turbine } \\
\text { compartment }\end{array}$ & $\begin{array}{l}1.25 \\
1.20\end{array}$ & 3.603 & $\begin{array}{l}0.73 \\
0.70\end{array}$ & 2.475 & $\begin{array}{l}1.31 \\
1.50\end{array}$ & 13.84 \\
\hline 13 & Steam pressure before eighth turbine compartment & $\begin{array}{l}0.92 \\
0.91\end{array}$ & 1.164 & $\begin{array}{l}0.54 \\
0.58\end{array}$ & 3.696 & $\begin{array}{l}0.96 \\
0.93\end{array}$ & 3.692 \\
\hline 14 & Steam pressure before ninth turbine compartment & $\begin{array}{l}0.214 \\
0.170\end{array}$ & 8.726 & $\begin{array}{l}0.132 \\
0.100\end{array}$ & 6.340 & $\begin{array}{l}0.221 \\
0.160\end{array}$ & 13.05 \\
\hline 15 & Steam pressure before turbine condenser & $\begin{array}{l}0.0686 \\
0.0590\end{array}$ & 1.912 & $\begin{array}{l}0.0470 \\
0.0335\end{array}$ & 2.697 & $\begin{array}{l}0.0668 \\
0.0575\end{array}$ & 2.002 \\
\hline 16 & Steam pressure after first turbine compartment & $\begin{array}{l}407.1 \\
411.9 \\
\end{array}$ & 0.904 & $\begin{array}{l}398.2 \\
400.3 \\
\end{array}$ & 0.395 & $\begin{array}{l}407.3 \\
412.0 \\
\end{array}$ & 0.884 \\
\hline 17 & Steam pressure after second turbine compartment & $\begin{array}{l}358.7 \\
359.3\end{array}$ & 0.157 & $\begin{array}{l}351.0 \\
349.6\end{array}$ & 0.359 & $\begin{array}{l}358.4 \\
359.8\end{array}$ & 0.355 \\
\hline 18 & Steam pressure after third turbine compartment & $\begin{array}{l}493.3 \\
491.1 \\
\end{array}$ & 0.404 & $\begin{array}{l}488.9 \\
495.4 \\
\end{array}$ & 1.216 & $\begin{array}{l}491.4 \\
490.3\end{array}$ & 0.197 \\
\hline 19 & Steam pressure after fourth turbine compartment & $\begin{array}{l}419.7 \\
435.3\end{array}$ & 3.899 & $\begin{array}{l}416.6 \\
432.2 \\
\end{array}$ & 3.899 & $\begin{array}{l}417.8 \\
415.0\end{array}$ & 0.698 \\
\hline 20 & Steam pressure after fifth turbine compartment & $\begin{array}{l}305.6 \\
298.1 \\
\end{array}$ & 1.866 & $\begin{array}{l}304.5 \\
307.3 \\
\end{array}$ & 0.696 & $\begin{array}{l}304.1 \\
301.5 \\
\end{array}$ & 0.656 \\
\hline 21 & Steam pressure after sixth turbine compartment & $\begin{array}{l}185.5 \\
177.2\end{array}$ & 3.114 & $\begin{array}{l}185.4 \\
175.3\end{array}$ & 3.798 & $\begin{array}{l}184.4 \\
187.6\end{array}$ & 1.182 \\
\hline 22 & Steam pressure after seventh turbine compartment & $\begin{array}{l}162.5 \\
156.9\end{array}$ & 2.117 & $\begin{array}{l}162.8 \\
166.8\end{array}$ & 1.517 & $\begin{array}{l}161.5 \\
154.8\end{array}$ & 2.511 \\
\hline 23 & Steam pressure after eighth turbine compartment & $\begin{array}{l}69.9 \\
70.0\end{array}$ & 0.055 & $\begin{array}{l}73.3 \\
70.0\end{array}$ & 2.493 & $\begin{array}{l}68.6 \\
75.0\end{array}$ & 4.799 \\
\hline 24 & Steam pressure after ninth turbine compartment & $\begin{array}{l}37.8 \\
38.5\end{array}$ & 0.533 & $\begin{array}{l}31.4 \\
29.3\end{array}$ & 1.571 & $\begin{array}{l}37.4 \\
38.2\end{array}$ & 0.530 \\
\hline 25 & Circulating water temperature after condenser & $\begin{array}{l}29.37 \\
30.20\end{array}$ & 1.248 & $\begin{array}{l}26.43 \\
26.35\end{array}$ & 0.126 & $\begin{array}{c}28.52 \\
29.5\end{array}$ & 1.464 \\
\hline 26 & $\begin{array}{l}\text { Temperature of condensate-feed water mixture } \\
\text { after condenser }\end{array}$ & $\begin{array}{l}37.2 \\
38.8\end{array}$ & 2.432 & $\begin{array}{l}31.1 \\
29.6\end{array}$ & 2.241 & $\begin{array}{l}36.8 \\
38.2\end{array}$ & 2.112 \\
\hline 27 & $\begin{array}{l}\text { Turbine condensate temperature after first low- } \\
\text { pressure heater }\end{array}$ & $\begin{array}{l}54.5 \\
55.7 \\
\end{array}$ & 0.895 & $\begin{array}{l}41.3 \\
46.4 \\
\end{array}$ & 3.861 & $\begin{array}{l}55.3 \\
55.3\end{array}$ & 0.027 \\
\hline
\end{tabular}


Continuation of Table 1

\begin{tabular}{|c|c|c|c|c|c|c|c|}
\hline 1 & 2 & 3 & 4 & 5 & 6 & 5 & 6 \\
\hline 28 & $\begin{array}{l}\text { Turbine condensate temperature after second low- } \\
\text { pressure heater }\end{array}$ & $\begin{array}{l}96.3 \\
95.4\end{array}$ & 0.706 & $\begin{array}{l}82.5 \\
83.9\end{array}$ & 1.043 & $\begin{array}{c}97.48 \\
95.7\end{array}$ & 1.334 \\
\hline 29 & $\begin{array}{l}\text { Turbine condensate temperature after third low- } \\
\text { pressure heater }\end{array}$ & $\begin{array}{l}137.6 \\
139.4\end{array}$ & 1.368 & $\begin{array}{l}119.3 \\
122.5\end{array}$ & 2.391 & $\begin{array}{l}138.9 \\
139.9\end{array}$ & 0.719 \\
\hline 30 & Turbine condensate temperature after deaerator & $\begin{array}{l}165.6 \\
164.4\end{array}$ & 0.901 & $\begin{array}{l}144.8 \\
148.5\end{array}$ & 2.763 & $\begin{array}{l}167.2 \\
164.5\end{array}$ & 2.052 \\
\hline 31 & $\begin{array}{l}\text { Feed water temperature after fourth high-pressure } \\
\text { heater }\end{array}$ & $\begin{array}{l}194.7 \\
198.7\end{array}$ & 1.991 & $\begin{array}{l}172.7 \\
175.3\end{array}$ & 1.301 & $\begin{array}{l}196.1 \\
200.4\end{array}$ & 2.142 \\
\hline 32 & $\begin{array}{l}\text { Feed water temperature after fifth high-pressure } \\
\text { heater }\end{array}$ & $\begin{array}{l}233.0 \\
236.6\end{array}$ & 1.800 & $\begin{array}{l}208.2 \\
209.6\end{array}$ & 0.720 & $\begin{array}{l}234.8 \\
238.8\end{array}$ & 2.013 \\
\hline 33 & $\begin{array}{l}\text { Feed water temperature after sixth high-pressure } \\
\text { heater }\end{array}$ & $\begin{array}{l}255.1 \\
261.9\end{array}$ & 3.411 & $\begin{array}{l}227.1 \\
230.5\end{array}$ & 1.719 & $\begin{array}{l}257.4 \\
264.3\end{array}$ & 3.471 \\
\hline 34 & Electric power generated by turbine unit generator & $\begin{array}{l}225.09 \\
227.09\end{array}$ & 2.398 & $\begin{array}{l}128.16 \\
124.98\end{array}$ & 3.820 & $\begin{array}{l}235.12 \\
235.73\end{array}$ & 0.730 \\
\hline 35 & $\begin{array}{l}\text { Feed water temperature after boiler condensate } \\
\text { cooler }\end{array}$ & $\begin{array}{l}273.7 \\
269.6\end{array}$ & 2.067 & $\begin{array}{l}255.1 \\
249.0\end{array}$ & 3.061 & $\begin{array}{l}270.7 \\
263.9\end{array}$ & 3.413 \\
\hline 36 & $\begin{array}{l}\text { Steam temperature after high-pressure water } \\
\text { economizer }\end{array}$ & $\begin{array}{l}337.3 \\
332.7 \\
\end{array}$ & 1.738 & $\begin{array}{l}324.3 \\
332.7 \\
\end{array}$ & 3.152 & $\begin{array}{l}337.3 \\
327.4\end{array}$ & 3.713 \\
\hline 37 & Saturated steam pressure after boiler drum & $\begin{array}{l}167.75 \\
166.95\end{array}$ & 0.636 & $\begin{array}{l}146.20 \\
144.17\end{array}$ & 1.623 & $\begin{array}{l}172.7 \\
172.2\end{array}$ & 0.435 \\
\hline 38 & Steam temperature before radiant superheater & $\begin{array}{l}358.2 \\
358.2\end{array}$ & 0.012 & $\begin{array}{l}352.5 \\
360.1\end{array}$ & 2.286 & $\begin{array}{l}359.3 \\
358.1\end{array}$ & 0.351 \\
\hline 39 & Steam temperature after radiant superheater & $\begin{array}{l}417.1 \\
413.3\end{array}$ & 1.138 & $\begin{array}{l}438.8 \\
436.3\end{array}$ & 0.738 & $\begin{array}{l}410.2 \\
407.6\end{array}$ & 0.782 \\
\hline 40 & erature after injection into primary & $\begin{array}{l}397.7 \\
399.2\end{array}$ & 0.376 & $\begin{array}{l}400.1 \\
401.5\end{array}$ & 0.358 & $\begin{array}{l}399.3 \\
405.6\end{array}$ & 1.568 \\
\hline 41 & $\begin{array}{l}\text { rature after first chain of middle } \\
\text { eater }\end{array}$ & $\begin{array}{l}447.1 \\
444.6\end{array}$ & 0.623 & $\begin{array}{l}457.2 \\
454.4 \\
\end{array}$ & 0.698 & $\begin{array}{l}446.7 \\
446.5 \\
\end{array}$ & 0.060 \\
\hline 42 & after first chain of outer platen & $\begin{array}{l}498.4 \\
494.3 \\
\end{array}$ & 1.019 & $\begin{array}{l}513.0 \\
506.6\end{array}$ & 1.602 & $\begin{array}{l}496.2 \\
492.8\end{array}$ & 0.859 \\
\hline 43 & $\begin{array}{l}\text { serature after injection into secondary } \\
\text { er }\end{array}$ & $\begin{array}{l}483.7 \\
483.7\end{array}$ & 0.012 & $\begin{array}{l}492.9 \\
493.7\end{array}$ & 0.189 & $\begin{array}{l}484.0 \\
488.9\end{array}$ & 1.224 \\
\hline 44 & $\begin{array}{l}\text { erature after second chain of middle } \\
\text { rheater }\end{array}$ & $\begin{array}{l}503.2 \\
501.3\end{array}$ & 0.483 & $\begin{array}{l}511.9 \\
512.5\end{array}$ & 0.140 & $\begin{array}{l}503.0 \\
504.9\end{array}$ & 0.464 \\
\hline 45 & $\begin{array}{l}\text { perature after second chain of outer } \\
\text { erheater }\end{array}$ & $\begin{array}{l}524.5 \\
518.4\end{array}$ & 1.516 & $\begin{array}{l}532.9 \\
528.4\end{array}$ & 1.135 & $\begin{array}{l}523.7 \\
522.7\end{array}$ & 0.261 \\
\hline 46 & rature after injection into tertiary & $\begin{array}{l}508.2 \\
509.5\end{array}$ & 0.334 & $\begin{array}{l}520.8 \\
519.4\end{array}$ & 0.341 & $\begin{array}{l}508.3 \\
512.1\end{array}$ & 0.943 \\
\hline 47 & Steam pressure after convection superheater & $\begin{array}{l}565.4 \\
566.3\end{array}$ & 0.222 & $\begin{array}{l}566.8 \\
566.9\end{array}$ & 0.036 & $\begin{array}{l}565.5 \\
566.8\end{array}$ & 0.322 \\
\hline 48 & Steam temperature after primary reheat & $\begin{array}{l}478.1 \\
481.3 \\
\end{array}$ & 0.801 & $\begin{array}{l}480.6 \\
485.8 \\
\end{array}$ & 1.297 & $\begin{array}{l}477.2 \\
476.8 \\
\end{array}$ & 0.094 \\
\hline 49 & $\begin{array}{l}\text { Steam temperature after injection into low- } \\
\text { pressure steam cooler }\end{array}$ & $\begin{array}{l}404.4 \\
410.6\end{array}$ & 1.543 & $\begin{array}{l}440.7 \\
441.7\end{array}$ & 0.254 & $\begin{array}{l}410.9 \\
417.4\end{array}$ & 1.618 \\
\hline 50 & Steam temperature after secondary reheat & $\begin{array}{l}516.9 \\
514.2 \\
\end{array}$ & 0.669 & $\begin{array}{l}531.4 \\
528.9\end{array}$ & 0.630 & $\begin{array}{l}522.5 \\
515.2\end{array}$ & 1.822 \\
\hline 51 & Steam temperature after tertiary reheat & $\begin{array}{l}584.1 \\
568.5\end{array}$ & 3.888 & $\begin{array}{l}578.0 \\
568.7\end{array}$ & 2.327 & $\begin{array}{l}582.2 \\
567.6\end{array}$ & 3.656 \\
\hline 52 & $\begin{array}{l}\text { Steam temperature after low-pressure water } \\
\text { economizer }\end{array}$ & $\begin{array}{l}111.1 \\
109.2\end{array}$ & 1.420 & $\begin{array}{c}98.9 \\
101.3\end{array}$ & 1.785 & $\begin{array}{l}112.1 \\
107.9\end{array}$ & 3.134 \\
\hline 53 & Gas temperature after primary tubular air heater & $\begin{array}{l}155.1 \\
149.3\end{array}$ & 1.767 & $\begin{array}{l}131.8 \\
139.9\end{array}$ & 2.417 & $\begin{array}{l}156.0 \\
146.1\end{array}$ & 2.983 \\
\hline 54 & Air temperature after secondary tubular air heater & $\begin{array}{l}324.9 \\
328.1\end{array}$ & 0.588 & $\begin{array}{l}289.0 \\
304.0\end{array}$ & 2.804 & $\begin{array}{l}328.4 \\
321.0\end{array}$ & 1.400 \\
\hline 55 & Primary steam flow rate after boiler & $\begin{array}{l}175.7 \\
184.2\end{array}$ & 3.398 & $\begin{array}{l}102.21 \\
101.96\end{array}$ & 0.099 & $\begin{array}{l}184.76 \\
186.61\end{array}$ & 0.740 \\
\hline 56 & $\begin{array}{l}\text { Flow rate of condensate-feed water mixture after } \\
\text { condenser }\end{array}$ & $\begin{array}{l}134.40 \\
154.07\end{array}$ & 9.838 & $\begin{array}{l}79.00 \\
77.74\end{array}$ & 0.629 & $\begin{array}{l}140.14 \\
161.17\end{array}$ & 10.52 \\
\hline
\end{tabular}


End of Table 1

\begin{tabular}{|c|c|c|c|c|c|c|c|}
\hline 1 & 2 & 3 & 4 & 5 & 6 & 5 & 6 \\
\hline 57 & $\begin{array}{l}\text { Gas temperature after high-pressure convection } \\
\text { superheater }\end{array}$ & $\begin{array}{l}775.4 \\
696.7\end{array}$ & 1.218 & $\begin{array}{l}661.3 \\
650.1\end{array}$ & 0.269 & $\begin{array}{l}753.1 \\
703.4\end{array}$ & 1.244 \\
\hline 58 & $\begin{array}{l}\text { Gas temperature after superheater of secondary } \\
\text { reheat }\end{array}$ & $\begin{array}{l}545.6 \\
458.5\end{array}$ & 2.614 & $\begin{array}{l}488.1 \\
447.1\end{array}$ & 1.231 & $\begin{array}{l}557.5 \\
457.1\end{array}$ & 3.014 \\
\hline 59 & $\begin{array}{l}\text { Gas temperature after superheater of primary } \\
\text { reheat }\end{array}$ & $\begin{array}{l}382.0 \\
339.6\end{array}$ & 1.590 & $\begin{array}{l}338.7 \\
313.3\end{array}$ & 0.954 & $\begin{array}{l}386.2 \\
332.4\end{array}$ & 2.018 \\
\hline 60 & $\begin{array}{l}\text { Gas temperature after high-pressure water } \\
\text { economizer }\end{array}$ & $\begin{array}{l}219.2 \\
207.0\end{array}$ & 0.613 & $\begin{array}{l}188.1 \\
192.5\end{array}$ & 0.217 & $\begin{array}{l}221.4 \\
202.4\end{array}$ & 0.952 \\
\hline
\end{tabular}

Table 2.Example of the optimization calculation of generating unit operation condition

\begin{tabular}{|c|c|c|c|}
\hline No & Parameter, measurement unit & Real condition & $\begin{array}{l}\text { Optimal } \\
\text { condition }\end{array}$ \\
\hline 1 & 2 & 3 & 4 \\
\hline 1 & Consumption of fuel burnt in boiler, $\mathrm{kg} / \mathrm{s}$ & 36.89 & 36.79 \\
\hline 2 & Excess air coefficient in boiler furnace & 1.21 & 1.21 \\
\hline 3 & Steam enthalpy decrease in first steam cooler, $\mathrm{kcal} / \mathrm{kg}$ & 18.11 & 21.86 \\
\hline 4 & Steam enthalpy decrease in second steam cooler, $\mathrm{kcal} / \mathrm{kg}$ & 10.39 & 7.13 \\
\hline 5 & Steam enthalpy decrease in third steam cooler, $\mathrm{kcal} / \mathrm{kg}$ & 10.90 & 9.73 \\
\hline 6 & Steam enthalpy decrease in steam cooler of steam reheat pipeline, $\mathrm{kcal} / \mathrm{kg}$ & 39.86 & 43.15 \\
\hline 7 & Head of feeding pump, $\mathrm{kgf} / \mathrm{cm} 2$ & 175.53 & 165.45 \\
\hline 8 & Head of circulating pump, $\mathrm{kgf} / \mathrm{cm} 2$ & 5.92 & 1.42 \\
\hline 9 & Cooling water flow rate before condenser, $\mathrm{kg} / \mathrm{s}$ & 10253 & 10972 \\
\hline 10 & Electric capacity at generator terminals, MW & 225.09 & 225.06 \\
\hline 11 & Primary steam temperature before turbine, $\mathrm{C}$ & 565.41 & 575.22 \\
\hline 123 & Secondary steam temperature before turbine, $\mathrm{C}$ & 584.05 & 584.98 \\
\hline 13 & Flue gas temperature after boiler, $\mathrm{C}$ & 155.14 & 155.80 \\
\hline 14 & Pressure in turbine condenser, $\mathrm{kgf} / \mathrm{cm} 2$ & 0.0686 & 0.0653 \\
\hline 15 & $\begin{array}{l}\text { Specific consumption of coal equivalent for electricity generation (net), } \\
\mathrm{gce} / \mathrm{kW} \cdot \mathrm{h}\end{array}$ & 368.58 & 356.75 \\
\hline 16 & Net efficiency of generating unit & 33.33 & 34.44 \\
\hline
\end{tabular}

\section{Conclusions}

The paper describes an improved technique developed by the author for identification of mathematical model parameters of complex thermal power equipment. The calculations show that the technique allows the more effective a) detection of gross errors in measurements of control parameters used for identification of mathematical model parameters of the studied equipment, b) assessment of correctness and amendment of errors in mathematical model construction and c) improvement of the accuracy of identification problem solution.

Besides, the paper describes criteria to assess the identification problem solution accuracy for both individual measurements of control parameters and the total discrepancy of all parameters in the considered operation conditions. The suggested technique also allows assessing an additional error due to imperfection of the standard calculation methods and assumptions in the mathematical model of the studied TPU besides the errors due to the accuracy of sensors used for equipment tests. 
The improved technique for identification of mathematical model parameters was tried on the detailed mathematical model of the $225 \mathrm{MW}$ present-day generating unit that was constructed by the author. The paper presents results of the problem solution on identification of mathematical model parameters of the generating unit and an example of the optimization calculation of real operation condition in order to decrease specific consumption of coal equivalent for electricity generation and improve the generating unit efficiency.

\section{References}

1. Levental G.B., Popyrin L.S. Optimization of thermal power units - M.: - Energy, 1970. - 352 p. (in Russian) 2. Popyrin L.S., Samusev V.I., Epelstein V.V. Automation of mathematical modeling of thermal power units. - M.: Nauka, 1981. - 236 p. (in Russian)

3. Vulman F.A., Koryagin A.V., Krivoshei M.Z. Mathematical modeling of steam turbine thermal diagrams on digital computers. - M.: Machinostroenie, 1985. - 111 p. (in Russian)

4. Palagin A.A. Design automation of turbine thermal diagrams. - Kiev: Naukova dumka, 1983. - 160 p. (in Russian)

5. Computer-aided design of thermal diagrams and calculation of variable-load operation of steam turbine units at TPP and NPP / Borovikov V.M., Kazarov S.A., Kutakhov A.G. et al. // Thermal Engineering. - 1993. No. 3. P.5-9. (in Russian)

6. Gamm A.Z., Kolosok I.N. Detection of bad data in telemetry for ADCS of electric power systems on the basis of test equations. Preprint ISEM SO RAN, Irkutsk, 1998. - 49 p. (in Russian)

7. Novitsky N.N. Estimation of hydraulic circuit parameters. - Novosibirsk: Nauka, 1998. - 215 p. (in Russian)

8. Nozdrenko G.V., Ovchinnikov Yu.V. Optimization of in-plant conditions of CHPP in the computerized process control system // Problems and methods of power system control: Collected papers. - Novosibirsk, 1982. - P. 2127. (in Russian)

9. Krokhin G.D., Suprunenko M.Ya. State diagnostics of power facilities at TPP (arrangement of experiments) // Proceedings of the 3rd international scientific-technical conference "Topical problems of electronic instrument engineering APEIE-96”. Vol. 5, p. 105-111. (in Russian) 10. Dekanova N.P., Kler A.M. Optimization problems in the study of thermal power plants // Approximate methods of analysis and their applications. - Irkutsk: SEI SO AN SSSR, 1989. - pp. 22-43. (in Russian)

11. Kler A.M., Dekanova N.P., Mikheev A.V. Optimization problems in real-time control of CHPP operation conditions // Optimization methods and their applications: Abstracts of the 10th Baikal School Workshop. - Irkutsk: SEI SO RAN, 1995. - P. 80-84. (in Russian)

12. Mikheev A.V. State estimation and identification of parameters of the steam boiler TP-81 (CHPP-9) // Systems research in energy. Proceedings of Young
Scholars at ISEM SB RAS. Issue 29. - Irkutsk: ISEM SO RAN, 1999. - P. 143-148. (in Russian)

13. Dekanova N.P., Mikheev A.V. Detection of bad measurements of parameters of CHPP operation // Optimization methods and their applications. Materials of the 11th Baikal School Workshop. Irkutsk: SEI SO RAN, 1998. - P. 79-82. (in Russian)

14. Kler A.M., Maximov A.S., Stepanova E.L. et al: Optimizing the Operating Modes of Cogeneration Stations Taking Actual State of Main Equipment into Account, Thermal Engineering, 2009, Vol. 56, No. 6, pp. 500-505.

15. Kler, A.M., Maximov, A.S., Stepanova, E.L. Highspeed mathematical models of cogeneration steam turbines: optimization of operation in heat and power plants, Thermophysics and Aeromechanics, 2006, Vol. 13, No.1, pp. 143-150.

16. Kobzar A.I. Applied mathematical statistics. For engineers and scientists. - 2nd corrected edition. - M.: FIZMATLIT, 2012. - 816 p. (in Russian)

17. Alexeyuk V.E. Improvement of the technique for identification of mathematical models based on the test results of a condensing turbine unit. Systems Research in Energy. Proceedings of Young Scholars at Melentiev Energy Systems Institute, Siberian Branch, Russian Academy of Sciences. Irkutsk: ISEM SO RAN, 2017, issue 47, pp. 42 - 55. (in Russian)

18. Alexeyuk V.E., Maximov A.S. Identification of the mathematical model of a condensing turbine unit based on test results / Proceedings of the All-Russian Scientific and Practical Conference with international participation "Improvement of energy production and utilization efficiency under Siberian conditions", Irkutsk: Izd-vo IrNITU, pp. 284 - 288, April 24 - 271, 2017. (in Russian)

19. Kler A.M., Mai V.A., Skripkin S.K. A system for computer-based creation of static and dynamic mathematical models of thermal power plants, Proceedings, $2^{\text {nd }}$ International Forum. Expert systems and computer simulation in energy engineering, Erlangen, Germany, March 17-20, 1992, pp. 22-4-1 22-4-3.

20. V.E. Alexeyuk, "An improved technique for identification of mathematical models of thermal power equipment," Energy Systems Research, Vol. 1, No. 3, pp. 53-60, 2018, http://dx.doi.org/10.25729/esr.2018.03.0007 